\title{
Metastatic Malignant Neoplasm in the Testis
}

National Cancer Institute

\section{Source}

National Cancer Institute. Metastatic Malignant Neoplasm in the Testis. NCI Thesaurus.

Code C4584.

A malignant neoplasm that has spread to the testis from another anatomic site. 